\title{
A Study on the College Students' Mental Health Education under the Influence of Network Discourse
}

\author{
Xuefeng Zhang \\ Chaoyang Teachers College, Chaoyang City, Liaoning Province, 122000 , \\ China
}

\begin{abstract}
Currently, the new economy, represented by the Internet, has achieved unprecedented prosperity. The contemporary college students, synchronized with the network, undoubtedly grow with the profound mark of the network era. The network discourses are frequently used among college students, which poses new challenges to the mental health education of the college students. In this paper, based on the author's learning and practical experience, we analyzed the impact of network discourse on the mental health of college students and their ideological education. On this basis, we put forward a new way to realize the mental health education for college students. The results of this paper can provide an effective basis for the scientific optimization of students' mental health education and attribute to realizing the innovative development of college mental health education in the network environment.
\end{abstract}

Keywords: network discourse; college students; mental health; educational mode

\section{Introduction}

Although the construction of network educational content creates a relatively rich learning resources for the students, the uncertainty of the network information, to a certain extent, restricts the construction of students' mental health educational content, and is not conducive to the construction of college mental health educational content[1]. Therefore, in the process of innovation and optimization of current educational mechanism, college educators should construct a targeted 
and applicable educational mode by analyzing the current situation of students' mental health education and combining with the actual needs of the institutions' development.

\section{Influence of Internet Discourse on College Students' Mental Health and Their Ideological Education}

\subsection{Healthy network discourse has a certain positive contribution to the psychological education of college students}

Network discourse refers to the popular discourse widely spread on the Internet, which originates from the folk but popularizes on the Internet. Its origin is the popular social life discourse. Internet discourse gets its rapid spread in the context of the high development of the Internet. From the overall social development of every country under Internet globalization, the positive incentives generated from the above-mentioned phenomenon to the growth of young students' mental health is primary, which includes positive energy obtained from the ideological and political education. Its main characteristics is: the healthy and humorous network discourse has a positive impact on college students' psychology, thoughts and behaviors[2]. For example, one network discourse reflecting the universal law of life development is: debut at the age of seven, improvement every day at the age of ten, cherishing lofty ideals at the age of twenty, determination of the beginning (professional) direction at the age of thirty, thriving at the age of forty, struggling at the age of fifty, returning home gloriously at the age of sixty, playing mahjong at the age of seventy, basking at the age of eighty, lying in bed at the age of ninety, and hanging on the wall at the age of one hundred. This healthy network discourse, considered as conversation topics when chatting, can leave people, especially the college students, obtain full inspiration of life development. Network discourse is the product of the development of the times, and is also a kind of popular ideology and psychological objective existence. The positive incentive and positive energy generated from the smooth and healthy network discourses to college students' and social youths' psychology, thoughts and behaviors are primary.

\subsection{Negative network discourse has a negative impact on college students mental health education}

Indeed, the network is a double-edged sword. Internet discourse gets rapid spread in the context of the rapid development of the Internet, whose negative effect on the college students' psychology, thoughts and behaviors is objective and unavoidable[3]. Negative and vulgar discourses, especially the false statements announced on microblog by the network large $\mathrm{V}$, have a profound influence on the young college students and society. Yellow information, pornography web and online games make college students addicted to network, which have a serious negative impact on college students' psychology, ideology and healthy 
growth.

The unrealistic network buzzwords about the ideal of life, namely "sleep until one naturally wakes up, count until ones' hands cramp", are money worship discourses, which only talk about money, and do not talk about ideal. Once these discourses become a popular trend, the negative impact will be generated on ideological and political education, and the implementation of education on the great rejuvenation dream of the Chinese nation. Therefore, the negative network discourse is a kind of social concept existence, which can have a negative influence on the psychology, thought and behaviors of college students, and the mental health education and the ideological and political education of educational main body. At the same time, it enlightens that the educator must not take the entire exclusion attitude towards the network because of the social harm generated from the negative information and network discourse[4].

\section{New Approaches to College Students' Psychological Health Education in Network Environment}

\subsection{Renew educational concepts, and bring the resultant force between tradition and modern, mental health and ideological political education into full play}

In the network environment, many new problems about the mental health education could arise in college. We need to study and explore them in theory and practice, and actively build a new mode of college students' mental health education in the network environment. Although the network mental health education has the advantages that the traditional mental health education cannot match with, the traditional mental health education has the advantages of relatively deep communication, continuous education and face-to-face education. Especially, when the students appear obvious mental disorders such as obsessivecompulsive disorder, anxiety disorder and depressive disorder and so on, the traditional mental health education can gradually and effectively educate and guide them[5]. Therefore, in the process of psychological health education of college students, we should combine the network and traditional mental health education according to the psychological development and personality characteristics of the college students, complement their advantages to bring the strengths into full play, continuously promote the development of mental health education, create a greater value of mental health education, and maximally meet the needs of college students' mental health.

In regards to the educational strategy and means, we should appropriately integrate mental health education into the process of ideological and political education, feel the students' cognitive style in the process of ideological and political education, comprehensively understand students' personality characteristics, ability property and temperament type, transfer our own educational concept into students' inner thoughts, and enhance the level of ideological and political education. The teaching methods of ideological and 
political education should be learned in the process of mental health education. The flexible teaching methods can be used to guarantee the proper development direction of students' mental health.

\subsection{Integrally plan, and implement systematic network mental health education}

Network mental health education is a huge and complex systematic engineering, which not only requires the scientific guidance of mental health educational concepts, but also needs our overall planning and comprehensive promotion to realize key breakthrough and construct three-dimensional all-round network mental health education mode[6]. First, the attractive websites should be established, which can meet the needs of college students. Mental health education website should be an important channel for college students to acquire mental health knowledge. The different needs of different grades of college students should be taken full account of in the design of website section and content. Extensive publicity and popularization of mental health knowledge should be conducted through a variety of online activities and network psychological testing to obtain scientific evaluation of college students' psychology. Lively pages and rich content should be created to attract students to participate, which attributes to improving the utilization ratio of the websites.

Second, network psychological counseling should be carried out. Network psychological counseling is an information interactive process that psychological counselor or psychological consultant provide psychological counseling services for the visitors with real identity and virtual identity via comprehensive information services function provided by computer networks. Network psychological counseling is characterized by free from space and time constraints, convenient implementation and economy, which can be not only a guide-type psychological counseling but also a self-service counseling. Online consultation can timely correct the cognitive deviation of the helpers to overcome their emotional disorders.

\subsection{Strengthen training and guidance, and establish a new-style mental health education working team}

Doing well the transformation and guidance of college students' psychology in the network age not only requires that mental health educators have the basic theory and professional skills of mental health education, and understand and scientifically analyze the effect of modern technologies such as the Internet on the ideology, emotion and life styles of college students, but also requires that the network technology is grasped and applied into the mental health education practice to make mental health education professional, vivid and full of contagious[7].

To establish a profession-based and relatively stable mental health education working team with full-time and part-time educators, it is necessary to bring college counselors into the mental health education system. Counselors are frontline staffs in college. They are familiar with the network and close to the students, 
who play a very important role in the growth process of college students. Colleges should strengthen the training and guidance of counselors, form the training system of counselors' mental health knowledge, regularly conduct business training, improve their theoretical level, professional level and professionalism, and bring their role in mental health education of college students into full play.

3.4 Reinforce the guidance and support to college students' psychological communities, and construct the interdependent network system for college students

The professional psychological teachers should be selected to strengthen the guidance to the community work, and to perform effective supervision to the works such as overall operation of the psychological community, co-ordination of major activities, and selection of community cadres. The enthusiasm of every member can be aroused through the organization of a variety of community activities, and the community organizers and participants can have some insights and make progress in these activities, which can better promote the smooth development of community work. At the same time, the psychological abnormal individuals among the students can be timely found and some help can be given to the individuals with psychological problems via the psychological community organization of college students and the training of the members, which can realize peer counseling and bring the self-education and self-service functions of the college students into full play.

\section{Conclusion}

Currently, in the process of innovation and construction of mental health educational mechanism in colleges, we should construct a network educational mechanism and realize the combination of mental health and network content through the understanding of the network environment. Through combination of these educational concepts, we can effectively broaden the access to educational resources, and improve mental health education resources, which makes mental health education have a good play in the complex network environment. At the same time, the mental health educators in colleges should recognize the challenges brought by the complex network environment to the students' mental health, optimize the ways of information access to the network resources, and change the traditional education mode, which provides an effective development path for the innovation of psychological health education mechanism under the influence of network discourse.

\section{References}

[1] SONG Baoping, TAI Yongdan. Investigation on positive mental health 
education of college students in network environment. Journal of Ideological \&Theoretical Education, (10), pp.118-120, 2014.

[2] HUANG Xipang. Psychological health education for college students in network environment. Journal of Chongqing University of Science and Technology (Social Sciences Edition), (05), pp.172-173, 2013.

[3] SHEN Xiaomei. Constructing a new mode of college students' psychological health education under the network environment. China Youth Research, (01), pp.113-116, 2012.

[4] JIANG Qiaoling, HU Kai. Research progress and tendency of college students' network mental health education. Modern University Education, (06), pp.81-86, 2011.

[5] ZHU Jun. The research on strategies for mental health education on college students under the network environment. Journal of Xinyang Normal University (Philosophy and Social Sciences Edition), (04), pp.52-55, 2011.

[6] TIAN Yimin. A summary of research on college students' network mental health education. South Comments, (12), pp.65-67, 2007.

[7] LIU Xiulun. Exploration of the approaches of college students' network mental health education. Journal of Ideological \& Theoretical Education, (05), pp.53-55, 2005. 